\title{
MULTICENTER STUDY OF PERIOPERATIVE EVALUATION FOR NONCARDIAC SURGERIES IN BRAZIL (EMAPO)
}

Claudio Pinho, Paulo C Grandini, Danielle M Gualandro, Daniela Calderaro, Maristela Monachini, Bruno Caramelli

$\overline{\text { Pinho C, Grandini PC, Gualandro DM, Calderaro D, Monachini M, Caramelli B. Multicenterric study of perioperative }}$ evaluation for noncardiac surgeries in Brazil (EMAPO). Clinics. 2007;62(1):17-22.

INTRODUCTION: The accuracy of perioperative evaluation methods available is better than chance, but their performance is not ideal.

OBJECTIVES: To compare a new evaluation method (EMAPO) to the American College of Physicians method for determining the risk of cardiovascular complications in noncardiac surgeries and to look for new influencing variables.

METHODS: Evaluations through EMAPO and the American College of Physicians method were employed for 700 patients. Cardiac events and deaths were recorded, the risk variables related to the occurrence of complications were verified, and the models were compared by analyzing the areas under the receiver operating characteristic curves.

RESULTS: Mortality rate was 3.4\%, and the incidence of cardiovascular complications was 5.3\%. Renal failure $(P=0.01)$, major surgery $(P=0.004)$, and emergency surgery $(P=0.003)$ were independently related to the occurrence of cardiovascular complications. The two methods produced similar results.

CONCLUSION: EMAPO is as good as the American College of Physicians method in determining the risk of cardiovascular complications in noncardiac surgeries. New variables related to surgical risk were identified.

KEYWORDS: Cardiac risk. Noncardiac surgery. Algorithms. Cardiovascular complications. Risk factors.

There were 2,747,254 hospitalizations for surgical interventions in Brazil in 2000. The mortality rate associated with these hospitalizations was $2.1 \%$, and the average period of hospitalization was 4.6 days, generating a cost of roughly 750 million dollars. ${ }^{1}$ In the United States, $3 \%$ to $10 \%$ of the patients undergoing surgical intervention have some sort of complication, and of the deaths that occur in the postoperative period, $40 \%$ have a cardiovascular cause. ${ }^{2}$

Perioperative evaluation consists of a set of medical procedures performed before, during, and after the surgery to establish the degree of risk and to propose strategies for

Pontifical Catholic University of Campinas - Campinas/SP, Brazil. Interdisciplinary Medicine in Cardiology Unit, Heart Institute, University of São Paulo - São Paulo/SP, Brazil.

Email: bcaramel@usp.br

Received for publication on August 08, 2006.

Accepted for publication on October 16, 2006. reducing the incidence of cardiovascular complications. ${ }^{3-}$ ${ }^{26}$ The existing evaluation methods are based on studies that consider the impact of clinical and surgical characteristics on the postoperative evolution. The currently available evaluation methods have limitations because they leave out certain diseases, do not adopt modern diagnostic criteria and treatment options for others, and do not consider the extent of the surgery or the functional capacity. The accuracy of these methods is better than chance, but their performance is not ideal. The American College of Physicians (ACP) method is the most widely used method internationally, but it also has problems, ${ }^{6}$ eg, the wide range of different risk levels-particularly that of the intermediate level-in which different patients with clearly different risk profiles are classified in the same category.

The objectives of this study were to determine the risk profile and the incidence of perioperative complications in 
a Brazilian population and to compare an international evaluation method (ACP) with a new one called EMAPO (Multicenter Study of Perioperative Evaluation), which considers diseases that were not mentioned in the previous guidelines and modern treatment options in order to determine new clinical variables associated with cardiovascular complications.

\section{Population}

After approval by the local ethics committee, all consecutive patients older than 15 years referred for noncardiac surgeries, for whom perioperative evaluation was requested in the period between February 2001 and May 2002 in 3 centers (1 university hospital and 2 private clinics: Hospital das Clínicas, São Paulo University Medical School, Clinicor Clinic of Ribeirão Preto, and Ritmocordis Clinics of Valinhos) were studied. Patients who did not undergo surgery for any reason were excluded.

\section{METHODS}

The patients were evaluated through the method proposed by the EMAPO Project (Multicenter Study of Perioperative Evaluation of SOCESP - Society of Cardiology of the State of São Paulo). This method proposes calculating the cardiovascular risk index by adding the accumulated points that correspond to the presence of risk factors described previously and new variables that were added based on the clinical experience of the authors (Appendix).5,6,27 Additionally, EMAPO proposes a new classification, stratifying the perioperative risk into 5 levels according to the expected complication rate (Table 1 ).

Table 1 - Complication risk index according to the EMAPO

\begin{tabular}{lll}
\hline Risk Status & Total Score & $\begin{array}{l}\text { Expected Cardiac } \\
\text { Complications }\end{array}$ \\
\hline Very low & 0 & $<1 \%$ \\
Low & Up to 5 & $<3 \%$ \\
Moderate & From 6 to 10 & $<7 \%$ \\
Elevated & From 11 to 15 & $7 \%-13 \%$ \\
Very elevated & Above 15 & $>13 \%$ \\
\hline
\end{tabular}

EMAPO = Multicenter Study of Perioperative Evaluation

The same population was also evaluated using the American College of Physicians (ACP) criteria, which stratifies the perioperative risk into 3 levels according to the expected complication rate. ${ }^{6}$

The patients were monitored until discharge, and cardiac events and deaths were recorded. The cardiac events considered were ischemic events (unstable angina and myo- cardial infarction), embolic events, cardiac arrhythmias, and others. Cardiac events were defined as previous reported. ${ }^{8}$

\section{Statistical Analysis}

We estimated that the sample to be studied should have roughly 700 individuals. The risk variables were descriptively analyzed, and their relationship to the occurrence of perioperative cardiac complications was subsequently verified. Although some patients presented more than 1 complication, such patients were reckoned in the same manner as patients with a single complication. The chi-square method was used for this first analysis. Multivariate analysis was performed based on the variables identified in the univariate model. A $P$ value lower than or equal to 0.05 was considered statistically significant.

Both methods were then compared according to criteria of sensitivity and specificity using the areas under the receiver operating characteristic (ROC) curve. ${ }^{28-30}$

\section{RESULTS}

Seven hundred patients with a mean age of 56 years (18 to 96 years) were evaluated. The majority of these patients were women $(59.1 \%)$, and the presence of clinically detectable cardiac disease was described in $52 \%$. Regarding the type of surgery, $95 \%$ were elective, $4 \%$ urgent, and $0.4 \%$ emergency surgery. The average hospitalization period was 3.6 days (1 to 72 days).

The evaluation with the EMAPO method yielded a mean score of 3.5 points (within a range of 0 to 33 ), and patients with low and very low risk prevailed (83\%). The evaluation of the same sample by the ACP method resulted in a mean score of 2.0 points ( 0 to 20 ) and the patients with low risk $(94.4 \%)$ also prevailed.

The mortality rate was $3.4 \%$. Perioperative complications were observed in 64 patients $(9.1 \%)$. There were 42 cardiovascular events in 37 patients $(5.3 \%)$ as follows: 16

Table 2 - Risk level classification and cardiovascular complications (CC)

\begin{tabular}{lllll}
\hline & $\begin{array}{l}\text { EMAPO } \\
\text { Patients (\%) }\end{array}$ & $\mathrm{CC}(\%)$ & $\begin{array}{l}\text { ACP } \\
\text { Patients (\%) }\end{array}$ & $\mathrm{CC}(\%)$ \\
\hline Very Low & $370(52.9)$ & $11 / 370(3.0)$ & - & - \\
Low & $211(30.1)$ & $12 / 211(5.7)$ & $661(94.4)$ & $34 / 661(5.1)$ \\
Moderate / & $64(9.1)$ & $10 / 64(15.6)$ & $35(5.0)$ & $2 / 35(5.7)$ \\
Intermediate & & & & $1 / 4(25.0)$ \\
Elevated / High & $37(5.3)$ & $1 / 37(2.7)$ & $4(0.6)$ & - \\
Very Elevated & $18(2.6)$ & $3 / 18(16.7)$ & - & - \\
\hline
\end{tabular}

EMAPO = Multicenter Study of Perioperative Evaluation

$\mathrm{ACP}=$ American College of Physicians method 


\section{RISK FACTORS - VARIABLES:}

\section{Minor:}

( ) Inactive and bedridden patient

( ) Systemic arterial hypertension with left ventricular hypertrophy and ST-T alteration

( ) Previous ischemic stroke (less than 3 months)

( ) Diabetes mellitus associated with nephropathy/cardiopathy or use of insulin

( ) Chronic coronary disease with negative treadmill exercise test (less than 3 months)

( ) Intraperitoneal, intrathoracic, aortic and its branches, or major orthopedic surgery

( ) Presence of asymptomatic aortic aneurism, surgery not suggested

( ) Age above 70 years

( ) Acute myocardial infarction (more than 6 months)

( ) Acute pulmonary edema secondary to congestive heart failure (more than a week)

( ) Chronic atrial fibrillation, paroxysmal atrial tachyarrhythmias and documented unsustained ventricular tachycardias

( ) Poor general medical status: ( ) $\mathrm{K}<3.0 \mathrm{mEq} / \mathrm{L}$ or $\mathrm{HCO}_{2}<20 \mathrm{mEq} / \mathrm{L}$

( ) $\mathrm{pO}_{2}<60$ torr or $\mathrm{pCO}_{2}>50$ torr

( ) urea $>50 \mathrm{mg} / \mathrm{dL}$ or creatinine $>2.3 \mathrm{mg} / \mathrm{dL}$

( ) elevated AST or active hepatic disease

\section{Moderate:}

( ) Acute myocardial infarction (less than 6 months) and not in the acute phase

10 points

( ) Angina pectoris currently stable

10 points

( ) Unstable angina pectoris episode (less than 3 months), currently absent

10 points

( ) Acute pulmonary edema secondary to congestive heart failure

(less than a week)

10 points

( ) Sustained supraventricular tachyarrhythmias with elevated ventricular response

Documented sustained repetitive ventricular arrhythmia / history of ventricular fibrillation / Aborted sudden death episode (more than 3 months) /

Carrier of implantable automatic defibrillator

10 points

10 points

( ) Canadian Cardiovascular Society Angina classification - class III

10 points

( ) Emergency surgery

( ) Transplant surgery. Vital organ recipient: kidney and liver

10 points

( ) Severe mitral stenosis

10 points

\section{Major:}

( ) Canadian Cardiovascular Society Angina classification - class IV

20 points

( ) Critical aortic stenosis

20 points

( ) Congestive heart failure class IV

20 points

( ) Acute myocardial infarction (acute phase)

20 points

( ) Recent episode of ventricular fibrillation or aborted sudden death in noncarrier of implantable automatic defibrillator

20 points

( ) Transplant surgery. Vital organ recipient: lung

20 points

EMAPO = Multicenter Study of Perioperative Evaluation

Figure 1 - Risk factors for perioperative complications and respective points in the EMAPO project 
ischemic, 10 arrhythmic, 6 embolic, 2 congestive, and 8 nonspecified cardiovascular etiologies. Among the patients that presented complications, $37.5 \%$ died (Table 2).

The significance of the variables used in the EMAPO questionnaire regarding the existence of cardiac complications during the perioperative period was determined. In the univariate analysis, the statistically significant variables were detectable cardiopathy, poor general medical status (Figure 1), urea $>50 \mathrm{mg} / \mathrm{dL}$ or creatinine $>2.3 \mathrm{mg} / \mathrm{dL}$, emergency surgery, major surgery, surgery duration $>4$ hours, blood loss $>1000 \mathrm{~mL}$, hospitalization $>3$ days, chronic coronary disease with negative noninvasive stress testing (less than 3 months), male gender, general anesthesia, myocardial infarction $<6$ months, aortic aneurism, and age $>70$ years. In the multivariate analysis, the variables related to renal failure $(P=0.016)$, major surgery $(P=0.004)$, and emergency surgery $(P=0.03)$ remained significant.

The ROC curves derived from patient data according to EMAPO and ACP methods were analyzed. In order for the two methods to be compared, the 5 levels of the EMAPO method were grouped in 3 categories: very low and low risks were compared with the ACP low risk; moderate was compared with the ACP intermediate risk; elevated and very elevated were compared with the ACP high risk. The ROC curves are represented in Figure 2.

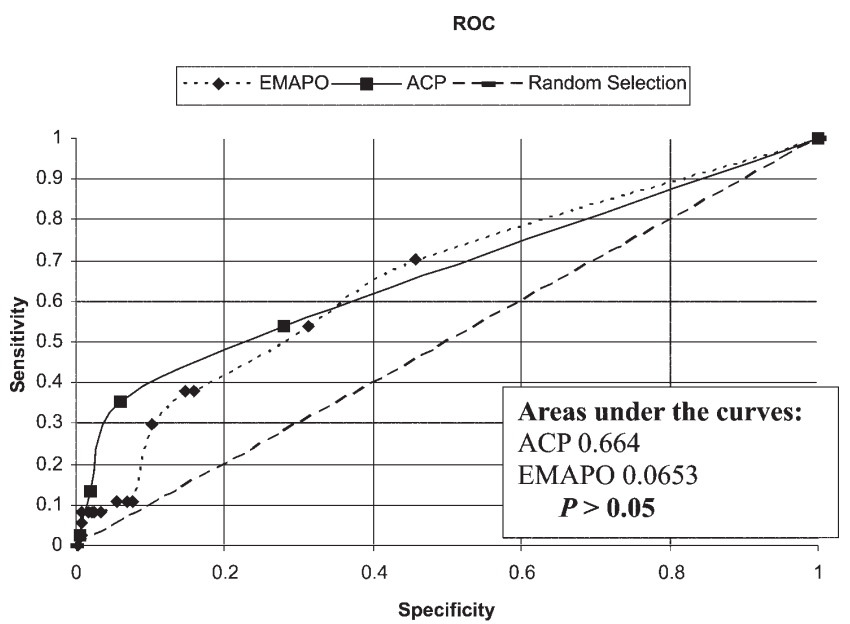

EMAPO $=$ Multicenter Study of Perioperative Evaluation $\mathrm{ACP}=$ American College of Physicians method

Figure 2 - ROC (receiver operating characteristic) curves according to the results from EMAPO and ACP evaluations

The comparison of the two methods showed that the areas did not differ and there was no significant difference between them in predicting the occurrence of cardiovascular complications. Besides that, new variables related to surgical risk were identified, such as male gender, aortic aneurysm and major surgery.

\section{DISCUSSION}

The majority of patients in our study was classified within the low risk group for perioperative cardiovascular complications. Nevertheless, we observed a high overall incidence of perioperative cardiovascular complications (5.3\%). The accuracy of perioperative evaluation methods available today is low, limiting our ability to take measures that would reduce cardiovascular complications.

Gilbert et al compared the perioperative evaluation methods used in clinical practice in 2035 patients. These methods were the ACP, the American Society of Anesthesiologists Index (ASA), the Canadian Cardiovascular Society Index, and the Goldman Index. In this population, $30 \%$ of the patients underwent low risk surgeries (ophthalmologic, superficial, and endoscopic), and cardiac complications occurred in $6.4 \%$ of patients. By comparing the accuracy of the methods using the ROC curve analysis, the authors concluded that all of them have limited accuracy and no method was better than the others. The authors suggest that more efficient methods are needed to prevent the occurrence of perioperative cardiovascular complications and that other clinical variables should be considered during the evaluation of risk. ${ }^{31}$ Consequently, we tried to create a new score to predict cardiac complications.

Existing methods of perioperative evaluation were developed by choosing variables previously described in the literature as predictors of perioperative events and giving points in order to create a score. The EMAPO was designed by updating variable definitions and adding new ones based on clinical experience, and it was as good as the ACP method in predicting cardiac events. Additionally, in the EMAPO model, major surgery was significant as a predictor of cardiac complications; this variable is not considered in the ACP model.

The intermediate risk of the ACP model includes patients with a wide risk range (chance of cardiac complications between $3 \%$ and $15 \%$ ). By proposing an extra 2 risk levels for cardiovascular complications, the EMAPO method intended to split the two most important strata, low risk and high risk, into 2 groups to disclose the differences in these very heterogeneous groups. However, this strategy failed, since no increased risk levels were identified, probably because of the relatively small number of patients in each group. Although the efficacy of EMAPO is similar to that of ACP, the execution of the former is more complex because of the number of items and consequently the amount of information needed. Besides that, as this is a new score, there are no guidelines regarding the strategy to be taken in order to minimize the cardiac risk for each category of patients. 
As the cost of hospital expenditures increases, the reduction of perioperative complication incidence becomes mandatory, because complications often result in a longer hospitalization period and in subsidiary exams and other medical interventions. , $^{3,7,8,32}$

More studies are needed to improve our ability to determine which patient has more cardiac risk after noncardiac surgery. The division of the intermediate risk into a more narrow risk range may be the first stage in this direction.

\section{ACKNOWLEDGEMENTS}

To SOCESP - Sociedade de Cardiologia do Estado de São Paulo (Society of Cardiology of the State of São Paulo), for the support given for the execution of this clinical study.

\section{RESUMO}

Pinho C, Grandini PC, Gualandro DM, Calderaro D, Monachini M, Caramelli B. Estudo multicêntrico de avaliação perioperatória para operações não cardíacas (EMAPO). Clinics. 2007;62(1):17-22.

INTRODUÇÃO: A precisão dos métodos de avaliação perioperatória disponíveis é melhor que o acaso, porém está longe do ideal.

OBJETIVOS: Comparar um novo método de avaliação perioperatória (EMAPO) ao método do American College of Physicians para determinar o risco cardíaco em cirurgias não cardíacas e buscar novas variáveis envolvidas na determinação deste risco.

MÉTODOS: O EMAPO e o método do American College of Physicians foram aplicados em 700 pacientes. A ocorrência de eventos cardíacos e de mortes foi documentada, a relação entre as variáveis de risco e as complicações foi estabelecida e os métodos foram comparados analisando as áreas sob a curva ROC.

RESULTADOS: A mortalidade foi $3.4 \%$ e a incidência de complicações cardiovasculares 5.3\%. A presença de insuficiência renal $(p=0.01)$, cirurgia de grande porte $(p=0.004)$ e cirurgia de emergência $(\mathrm{p}=0.003)$ se correlacionaram com a ocorrência de complicações cardiovasculares na análise multivariada. Não houve diferença entre os dois métodos. CONCLUSÕES: O EMAPO é tão eficaz quanto o método do American College of Physicians para determinar o risco de complicações cardiovasculares em cirurgias não cardíacas. Novas variáveis relacionadas com o risco perioperatório foram encontradas.

UNITERMOS: Avaliação perioperatória. Risco cardíaco. Algorítimos. Fatores de risco. Complicações cardiovasculares.

\section{REFERENCES}

1. Ministério da Saúde;SUS - DATASUS - Morbidade. www.datasus.gov.br (Accessed 20/08/2002).

2. Simon HU, Blaustein AS, Wexler LF. Evaluation and treatment of the perioperative patient. In: Crawford $\mathrm{MH}$, editor. Current diagnosis \& treatment in cardiology, $2^{\text {nd }}$ ed. United States of America: McGrawHill; 2003. p. 595-609.

3. Mangano DT, Layug EL, Wallace A, Tateo I. Effect of atenolol on mortality and cardiovascular morbidity after noncardiac surgery. N Engl J Med. 1996;335:1713-20.

4. Rao TL, Jacobs KH, El-Etr AA. Reinfarction following anesthesia in patients with myocardial infarction. Anesthesiology. 1983;59:499-505.

5. Eagle KA, Berger PB, Calkins H, Chaitman BR, Ewy GA, Fleishmann $\mathrm{KE}$, et al. ACC/AHA Guideline update for perioperative cardiovascular evaluation for noncardiac surgery. Report of the American College of Cardiology/American Heart Association Task Force on Practice Guidelines (Committee to Update the 1996 Guideline on Perioperative Cardiovascular Evaluation for Noncardiac Surgery). Circulation. 2002;105:1257-67.
6. Guidelines for assessing and managing the perioperative risk from coronary artery disease associates with major noncardiac surgery. Report of the American College of Physicians. Ann Intern Med. 1997;127:30912 .

7. Poldermans D, Boersma E, Bax JJ, Thamson IR, Paelenck B, Vandeven LL, et al; Dutch Echocardiographic Cardiac Risk Evaluation Applying Stress Echocardiography Study Group. Bisoprolol reduces cardiac death and myocardial infarction high-risk patients as long as 2 years after successful major vascular surgery. Eur Heart J. 2001;22:1253-8.

8. Durazzo AE, Machado FS, Ikeoka DT, De Bernoche C, Monachini MC, Puech-Leão $\mathrm{P}$, et al. Reduction in cardiovascular events after vascular surgery with atorvastatin: a randomized trial. J Vasc Surg. 2004;39:96776.

9. Vanzetto G, Machecourt J, Blendea D, Faget D, Bowel E, Magne JL, et al. Additive value of thallium single-photon emission computed tomography myocardial imaging for prediction of perioperative events in clinically selected high cardiac risk patients having abdominal aortic surgery. Am J Cardiol. 1996;77:143-8. 
10. Eagle KA, Coley CM, Newell JB, Brewster DC, Darling RC, Strauss HW, et al Combining clinical and thallium data optimizes preoperative assessment of cardiac risk before major vascular surgery. Ann Intern Med. 1989;110:859-66.

11. Goldman L, Caldera DL, Nussbaum SR, Southwick FS, Krogstod D, Murray B, et al. Multifactorial index of cardiac risk in noncardiac surgical procedures. N Engl J Med. 1977;297:845-50.

12. Detsky AS, Abrams HB, Mclaughlin JR, Druker DJ, Sanon G, Johnston $\mathrm{N}$, et al. Predicting cardiac complications in patients undergoing noncardiac surgery. J Gen Intern Med. 1986;1:211-9.

13. Hollenberg M, Mangano DT, Browner WS, London MJ, Tubau JF, Tateo IM. Predictors of postoperative myocardial ischemia in patients undergoing noncardiac surgery. JAMA. 1992;268:205-9.

14. Shaw LJ, Eagel KA, Gerrsh BJ, Miller DD. Meta-analysis of intravenous dipyridamole-thallium-201 imaging (1985-1994) and dobutamine echocardiography (1991-1994) for risk stratification before vascular surgery. J Am Coll Cardiol. 1996;27:787-98.

15. Mangano DT, Goldman L. Preoperative assessment of patients with known or suspected coronary disease. N Engl J Med. 1995;33:1750-6.

16. Fleisher LA, Eagle KA. Screening for cardiac disease in patients having noncardiac surgery. Ann Intern Med. 1996;124:767-72.

17. Wirthlin DJ, Cambria RP. Surgery-specific considerations in the cardiac patient undergoing noncardiac surgery. Prog Cardiovasc Dis. 1998;40:453-68.

18. Bondenheimer MM. Noncardiac surgery in the cardiac patient: what is the question? Ann Intern Med. 1996;124:763-6.

19. Younis LT, Miller D, Chaitman BR. Preoperative strategies to assess cardiac risk before noncardiac surgery. Clin. Cardiol. 1995;18:447-54.

20. Leppo JA. Preoperative cardiac risk assessment for noncardiac surgery. Am J Cardiol. 1995;75:42D-51D.
21. Abraham as, Eagle KA. Preoperative cardiac risk assessment for noncardiac surgery. J Nucl Cardiol. 1994;1:389-98.

22. Bartels C, Bechtel JF, Hossmann V, Horsch S. Cardiac risk stratification for high-risk vascular surgery. Circulation. 1997;95:2473-5.

23. Potyk D, Raudaskoski P. Preoperative cardiac evaluation for elective noncardiac surgery. Arch Fam Med. 1998;7:164-73.

24. Chaitman BR, Miller DD. Perioperative cardiac evaluation fo noncardiac surgery noninvasive cardiac testing. Prog Cardiovasc Dis. 1998;40:405-18.

25. Roizen MF. More preoperative assessment by physicians and less by laboratory tests. N Engl J Med. 2000;342:204-5.

26. Schein OD, Katz J, Bass EB, Tielsch JM, Lubomski LH, Feldman MA, et al. The value of routine preoperative medical testing before cataract surgery. N Engl J Med. 2000;342:168-75.

27. ACC/AHA Guidelines for the management of patients with valvular heart disease. J Am Coll Cardiol. 1998;32:1486-588.

28. Hanley JA, McNeil BJ. The meaning and use of the area under a receiver operating characteristic (ROC) curve. Radiology. 1982;143:29-36.

29. Hanley JA, McNeil BJ. A method of comparing the areas under receiver operating characteristic curves derived from the same cases. Radiology. 1983;148:839-43

30. Metodologia Estatística. www.analyse-it.com (Accessed 30/07/2002).

31. Gilbert K, Larocque BJ, Patrick LT. Prospective evaluation of cardiac risk indices for patients undergoing noncardiac surgery. Ann Intern Med. 2000;133:356-9.

32. Biccard BM, Sear JW, Foex P. Statin Therapy: a potentially useful perioperative intervention in patients with cardiovascular disease. Anaesthesia. 2005;60:1106-14. 